\title{
A CRIANÇA E O MAR: UM ESTUDO SOBRE O COTIDIANO DE CRIANÇAS NO CONTEXTO DA PESCA ARTESANAL ${ }^{1}$
}

\author{
Jéssica do Socorro Leite Corrêa ${ }^{2}$ \\ Luis Junior Costa Saraiva ${ }^{3}$
}

A construção dos saberes, frutos da interação entre as crianças, seus pares e o ambiente, a partir de um contexto específico, é de fundamental importância para compreender de que forma elas se comportam em situações distintas, considerando que estão ativamente no mundo enquanto atores sociais, produtores culturais, com uma imaginação recheada de significações e representatividade. Conhecer o cotidiano das crianças no contexto dos ambientes costeiros surgiu a partir do interesse em entender como são construídos seus saberes, as produções culturais e os reflexos dessa construção na relação com as questões ambientais e sociais.

O trabalho foi estruturado a partir da interpretação dos registros de pesquisa de campo realizada na Vila Tucum, no município de Bragança, em que acompanhamos a família de um pescador, conhecido como Zico (32 anos), durante duas viagens de pesca ${ }^{4}$. Nessa pescaria ele leva a família para acompanhalo em um racho na praia Lombo do cachorro, sua esposa Preta (30 anos), sua filha Leyli (10 anos), seu filho Pablo (3 anos) e Interadinho (16 anos) que é sobrinho de preta.

A pescaria que acompanhamos trata-se de um momento, podemos dizer pedagógico, realizado subjetivamente para aproximar as crianças da atividade de pesca. Outra característica dessa pesca especifica, aqui identificada como atividade conjunta, é sua duração, o tempo máximo do pescador no rancho com as crianças corresponde a três dias e sempre estão atentos as influências de maré, tornando a viagem mais tranquila.

Em relação à utilização de registros visuais Kossoy (2002, p. 38) destaca que "a realidade da fotografia reside nas múltiplas interpretações, nas diferentes "leituras" que cada leitor dela faz num dado momento". Nessa perspectiva os registros fotográficos apresentados no decorrer deste trabalho são aqueles que mais evocam o caráter intencional da pesquisa, direcionando sempre a sua identificação inicial, buscando dialogar o significado da vivência entre a Criança e o Mar. A fotografias foram

\footnotetext{
${ }^{1} \mathrm{O}$ presente ensaio foi elaborado a partir do trabalho de campo realizado na Vila Tucum, nos meses de janeiro e março de 2016.

${ }^{2}$ Mestranda do Programa de Pós-graduação em Linguagens e Saberes na Amazônia. Membro do Grupo de Estudos Socioambientais Costeiros (ESAC) Endereço eletrônico: etieljessica@ gmail.com.

${ }^{3}$ Doutor em Antropologia. Professor Adjunto FACED/UFPA, Campus de Bragança. Membro do grupo de Pesquisa Estudos Socioambientais Costeiros (ESAC). luisjsaraiva@yahoo.com.br.

${ }^{4}$ As viagens de pesca que destacamos ocorrem quando a família sai da Vila de residência em direção a praias próximas e lá ficam em ranchos por até três dias, para chegar a praia é preciso viajar de barco por um período aproximado de duas horas e meia.
} 
registradas pelos autores do ensaio e nosso objetivo é organizar as imagens nas curvas estruturais do texto escrito para que um complemente o outro, em harmonia.

Uma pescaria com a família torna-se a união de circunstâncias, pescar para a venda, para a alimentação e principalmente para a diversão, além da pescaria como espaço de produção de conhecimento. E agora nos é permitido viajar nas lembranças desses momentos de pesquisa de campo que foram registradas e guardadas dentro de um pequeno espaço visual.

Então é chegado o horário de partida e prontamente o menino caminha logo atrás do pai para ocupar seu espaço na canoa, de preferência bem ao seu lado. Enquanto fazemos o registro fotográfico os demais tripulantes estão se aproximando para subir no barco que ainda deverá ser empurrado até o córrego, após o registro, é possível observar o entorno e ver outras canoas, outras crianças, situações que se repetem, mas também que se distinguem. São crianças saindo e outras querendo ir, ajudando a organizar as coisas na canoa ou simplesmente observando.

De acordo com as colocações de Guattari (1990), as nossas ações, sejam no âmbito da ecologia mental, social ou ambiental, apresentam subjetividades que correspondem a uma essência específica relacionada ideologias. Nesse aspecto, compreender as situações observadas em campo e apresentadas a seguir nas imagens é mergulhar na subjetividade do pai para com os filhos, atitudes de quem pretende que eles desenvolvam habilidades de sobrevivência, de contato com os animais, de vencer o medo, do sentir, e outros, em um processo contínuo de aprendizagem.

Nessa perspectiva Cohn (2005), Corsaro (1985 e 2003) e Graue \& Walsh (2003) destacam que na pesquisa com crianças a sensibilidade do olhar, da aproximação e do desenvolvimento a tornam de fato participante, levando em consideração principalmente as especificidades de cada contexto. Ademais é válido ressaltar que assim como pesquisador busca uma aproximação com os atores sociais em campo, as crianças também querem vivenciar essa aproximação. Logo que chegamos da primeira viagem, o garoto queria ver as fotos, pediu a máquina fotográfica e ele mais que depressa começou a explorar aquele objeto, para além da vontade de ver as fotos, também desejava aprender a manuseá-la e fazer seus próprios registros. Como apresentado por (Oaklander, 1980), “(...) visão, som, tato, paladar e olfato. É através deles que experienciamos a nós mesmos e estabelecemos contato com o mundo". 

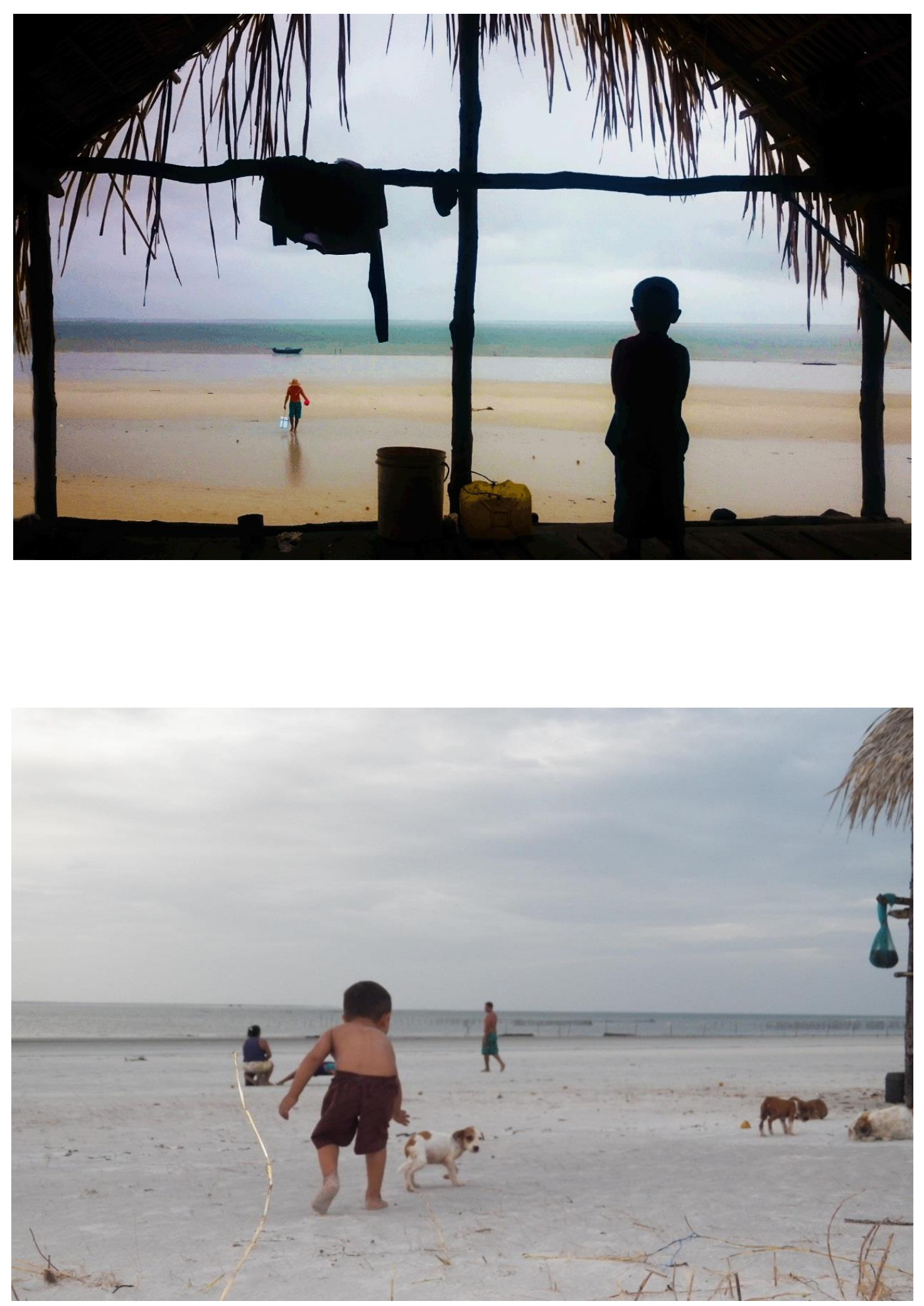

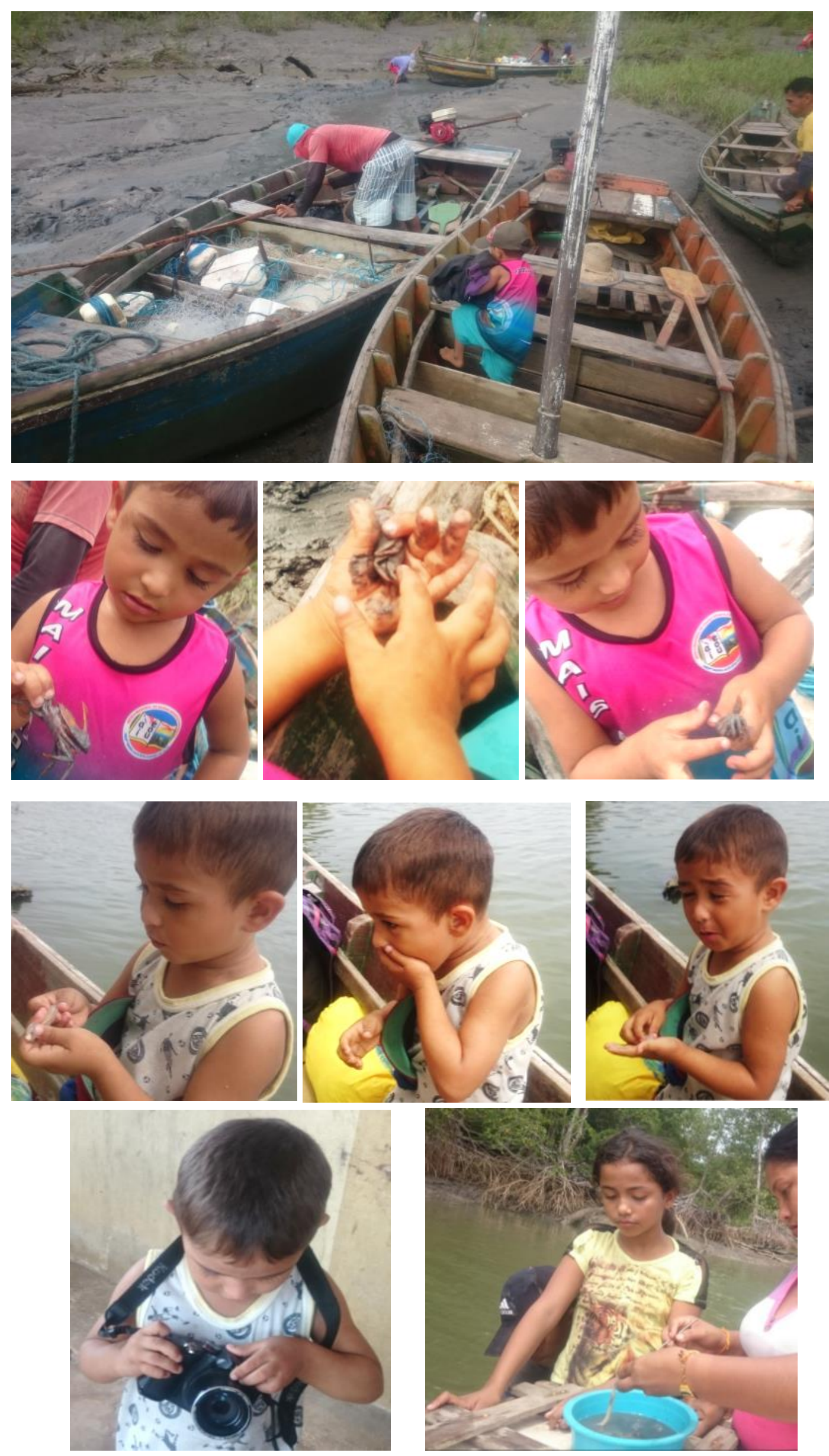


\section{REFERÊNCIAS BIBLIOGRÁFICAS}

COHN, Clarice. Antropologia da Criança. Rio de Janeiro: Zahar, 2005.

CORSARO, William A. Entrada no Campo, Aceitação e Natureza da Participação nos Estudos Etnográficos com Crianças Pequenas. Revista Edu. Soc, Campinas, vol. 26, n. 91, p443-464, Maio/Ago, 2005. Disponibilidade em: http://www.scielo.br/scielo.php?pid=S010173302005000200008\&script=sci_abstract\&tlng=pt. Acesso em: 20 out. 2016.

DUBOIS, Philippe. O ato fotográfico. In: O ato fotográfico e outros ensaios. Campinas: Papirus, 1993, pp. 56-107.

FAVRET-SAADA, Jeanne. Ser afetado. Cadernos de Campo, São Paulo, 13, 155-161, 2005.

GUATTARI. Félix. As Três Ecologias. 11ª ed. Campinas-SP: Papirus, 1990.

GRAUE, M. Elizabeth \& WALSH, Daniel J. Investigação etnográfica com crianças. Lisboa: Gulbenkian, 2003.

INGOLD, Tim. Estar Vivo: Ensaios sobre movimento, conhecimento e descrição. Petrópolis-RJ: Vozes, 2015.

KOSSOY, Boris. Realidades e Ficções na Trama Fotográfica. $3^{\text {a }}$ ed. Cotia-SP: Ateliê Editorial, 2002.

OAKLANDER, Violet. Descobrindo Crianças: a abordagem gestáltica com crianças e adolescentes. $15^{\mathrm{a}}$ ed. São Paulo: Sammus Editorial, 1980.

SARMENTO, Manoel Jacinto. Imaginário e Culturas da Infância. Instituto de Estudo da Criança. Universidade de Minho. Projeto POCTI/CED/49186/2002. Disponível em: http://titosena.faed.udesc.br/Arquivos/Artigos_infancia/Cultura\%20na\%20Infancia.pdf.Acessado em 30.03.2016. 